\title{
Pensar (com) a imagem: reflexôes teóricas para uma práxis historiográfica
}

\author{
Maria Cristina Correia L. Pereira* \\ Universidade de São Paulo, São Paulo-SP
}

Alloa, Emmanuel (Org.). Pensar a imagem. Tradução coordenada por Carla Rodrigues. Belo Horizonte: Autêntica, 2015.

Há algumas décadas as imagens deixaram de ser um elemento raro no universo dos historiadores, mera ilustração em capas de livros ou ornamento de ediçóes de luxo. A influência dos historiadores da chamada Escola dos Annales foi um passo decisivo nesse sentido: ao questionar a separação entre disciplinas, o contato com a Antropologia, a História da Arte e a Arqueologia contribuiu para que o conceito de fonte primária se expandisse do documento textual para todo tipo de vestígio material, incluindo, evidentemente, as imagens visuais. Mas não apenas isso, as imagens também começaram a ser vistas como legítimos objetos de estudo, uma vez que o objetivo principal da ciência histórica é compreender as sociedades humanas em suas produções e representaçóes.

A grande referência dessa mudança de paradigma - e que poderíamos chamar de figura totêmica dos estudos sobre as imagens
- é, sem dúvida, o historiador da arte alemão do início do século XX Aby Warburg. Ele defendia uma "kulturwissenschaftliche Bildgeschichte", uma "história das imagens do ponto de vista sociocultural", ${ }^{1}$ e em um de seus célebres estudos, de 1901, "A arte do retrato e a burguesia florentina", já indicava o caminho central de seu método de trabalho:

Florença, o berço da cultura urbano-mercantil moderna e autoconfiante, não nos legou somente retratos de pessoas há muito falecidas em uma vivacidade cativante e uma abundância incomparável. Em centenas de documentos arquivados já lidos e em outros milhares ainda não lidos, as vozes dos mortos continuam vivas. Uma postura de respeito histórico pode devolver o timbre a essas vozes inaudíveis, dado que nos damos ao trabalho de recuperar o vínculo natural entre palavra e imagem. ${ }^{2}$

\footnotetext{
${ }_{1}$ WARBURG, Aby. Heidnisch-antike Weissagung in Wort und Bild zu Luthers Zeiten. Heilderberg: Sitzungsberichte der Heildelbergen Akademie der Wissenchaften, 1920.

${ }^{2}$ WARBURG, Aby. A arte do retrato e a burguesia florentina. In: WARBURG, Aby. A renovação da Antiguidade pagã. Contribuiçôes científico-culturais para a história do Renascimento europeu. Traduçáo de Ma-
}

* Professora da Área de História Medieval do Departamento de História e do Programa de Pós-graduação graduação em História Social da USP; coordenadora do Laboratório de Teoria e História da Imagem e da Música Medievais (LATHIMM-USP). 
Para entender a inserção de retratos de burgueses em uma pintura de tema sacro, dedicava-se a uma longa exploração de testamentos e cartas, ex-votos e pinturas, sem estabelecer hierarquias, sem pretender traduzir uns por outros. Textos e imagens são analisados em suas especificidades e em seus vínculos — sua Zusammengehörigkeit ("conexidade", como traduziria Georges Didi-Huberman). ${ }^{3}$

A lição de mais de cem anos atrás ainda é válida e deve servir de mote: trabalhar com imagens e textos, levando em conta as diferenças entre esses dois universos. $\mathrm{O}$ segundo termo da equação — trabalhar com textos - não traz preocupação alguma aos historiadores, acostumados como estão a críticas internas, externas; a destrinchar motivos, causas, intençóes; a fazer leituras e interpretações. O primeiro termo, contudo, ainda causa certo desconforto. É necessário que se dominem as ferramentas adequadas,

rkus Hediger. Rio de Janeiro: Contraponto, 2013, p. 121-168, p. 123.

${ }^{3}$ Como diz literalmente Warburg: "Die natürliche Zusammengehörigkeit von Wort und Bild". WARBURG, Aby. Bildniskunst und florentinisches Bürgertum. I. Domenico Ghirlandajo in Santa Trinita, Die Bildnisse des Lorenzo de Medici und seiner Anghörigen. In: WARBURG, Aby. Gesammelte Schriften I. Die Erneuerung der heidnischen Antike. Kulturwissenschaftliche Beiträge zur Geschichte der europäischen Renaissance. Berlin: Akademie, 1998 [reimp. de 1932], p. 89-126. p. 96. A tradução por "conexidade" (DIDI-HUBERMAN, Georges. O que vemos, o que nos olha. Tradução Paulo Neves. São Paulo: 34, 1998, p. 181, n. 27) nos parece mais adequada do que "vínculo natural", segundo a traduçáo da obra para o português citada anteriormente. que estas não sejam transferidas automaticamente da prática com os textos. É muito limitador, por exemplo, tomar a imagem apenas por seu conteúdo iconográfico, que ela seja simplesmente "lida". Sua materialidade é fundamental, bem como as relaçôes com o lugar para o qual foi feita, seus usos e manipulações, suas funções e modos de funcionamento. Em suma, é fundamental pensar a imagem: pensar com e a partir dela.

Nesse sentido, é muito bem-vinda a recente tradução para o português pela editora mineira Autêntica da obra Pensar a imagem, organizada por Emmanuel Alloa, professor de Filosofia na Universidade da Basileia e de Estética na Universidade Paris 8, com base em um seminário realizado no Collège Internacional de Philosophie, em Paris, em 2007 e 2008, e publicada em 2010 por Les Presses du Réel. Nela estão presentes, divididos em quatro seções, dez artigos (além da introdução, a cargo do organizador) de alguns dos maiores especialistas nos estudos da imagem na atualidade, como Georges Didi-Huberman, Jacques Rancière e W. J. T. Mitchell. Preocupações de ordem teórica norteiam todos os textos, mas que isso náo seja visto como algo desabonador: apesar de não ser uma obra pensada por (e, em princípio, para) historiadores, sua leitura é muito recomendada para estes, por justamente permitir que se construa uma nova práxis, adequada a esse novo objeto que convida à transdisciplinaridade. Passemos a examiná-los brevemente.

$\mathrm{Na}$ introdução, Alloa faz mais que situar o lugar de origem do livro, ele também assenta as bases para as discussóes que se se- 
guem a respeito da natureza da imagem. $\mathrm{O}$ ponto central é a dualidade herdada desde a Antiguidade clássica quanto à concepção da imagem como pura representação ou como simples objeto — nas palavras de Platão (apud Alloa, p. 11), como imagem-cópia (eikón) ou como imagem-simulacro (eidolon) —; ou ainda, nas palavras do teórico da arte Louis Marin, como transparência ou opacidade (apud Alloa, p. 14). Essa dualidade foi muito explorada, por exemplo, pelo cristianismo, que pôde adotar e assumir as imagens reforçando a cisão entre imagem e ídolo: enquanto a primeira, por ser alegoria, é permitida (seu poder advindo da possibilidade de remeter ao protótipo), a imagem como ser-aí é rejeitada (por sua pretensão de se substituir ao protótipo).

Mas não é esse o objetivo de Alloa, e sim apontar os limites para essa dualidade tão ancorada na tradição ocidental. A imagem funciona no entre, e qualquer solução rápida que pretenda acantoná-la em uma definição excludente está fadada à incompletude. Como ele diz — e é uma das primeiras liçôes que dá — “as imagens exigem que a elas se dedique tempo" (p. 8). O caso emblemático por ele escolhido é o de uma fotografia da série Retratos Fictícios, de Keith Cottingham, de 1992: um retrato triplo de três adolescentes em busto que tem a particularidade de não ser de fato um retrato. Seus modelos não existem, trata-se de uma imagem "de síntese", "virtual”. A transparência absoluta é aqui impossível, uma vez que não existe o original a ser substituído, e a total opacidade também, já que não se pode dizer, como o artista minimalista Frank Stella, "what you see is what you see" (apud Alloa, p. 14), porque não se sabe o que se vê. A segunda grande lição é o constante questionamento que se há de fazer ao "tom de certeza" que se poderia ter em relação às imagens, de que se sabe (a verdade) em relação a elas. Como ele diz, retomando Didi-Huberman, não é questão de reconhecimento e sim de conhecimento. As imagens dão a pensar: são um objeto paradoxal "que se dá a ver em uma única e rápida olhada, sem, no entanto, jamais ser exaustivo no instante" (p. 16) - afinal, o "fim da imagem não pode ser reduzido a suas bordas materiais" (p. 16).

No primeiro capítulo do livro, Gottfried Boehm retoma a discussão da dualidade da imagem, e também aponta o equívoco dessa proposição, sustentando que a imagem é ao mesmo tempo transparência $e$ opacidade. A possibilidade da conjunção "e" é já uma característica — e uma evidência — de uma forma de pensar própria às imagens, por adição de opostos, por exemplo (como demonstra um caso bastante conhecido, o da imagem do coelho-pato evocada por Wittgenstein: no texto escrito somos obrigados a usar sinais gráficos, descriçóes para dar a entender algo que é simultaneamente ambos na imagem). Na esteira, entre outros, do historiador da arte francês Pierre Francastel, que falava de um "pensamento figurativo", 4 Boehm sustenta a existência de uma epistéme icônica, a escapar do exclusivismo do logos da linguagem. A imagem não é apenas referência, ela produz sentido (e daí seu interesse para o historiador, por exemplo).

${ }^{4}$ FRANCASTEL, Pierre. A realidade figurativa. São Paulo: Perspectiva, 1993, p. 3. 
Como ele conclui, em uma fórmula lapidar: "O que mostra — a imagem, em sua ocorrência - nos mostra como alguma coisa se mostra” (p. 38). A imagem mostra como (de que modo) ela mostra: essa é a lógica da mostração, o elemento fundamental da epistéme icônica. Cabe aos estudiosos — e aqui remetemo-nos especificamente aos historiadores - conhecer como esses mecanismos de funcionamento da imagem, a lógica da mostração, se dão em diferentes sociedades.

No capítulo seguinte Marie-José Mondzain retoma essa ideia e a retrabalha, lembrando que a imagem é “ao mesmo tempo uma operadora em uma relação e o objeto produzido por essa relação" (p. 39). Ou seja, é "como" e o "quê", poderíamos dizer. Isso a leva a fazer uma crítica profunda à atitude demasiado cômoda de confundir imagem com um simples objeto de uma narrativa (especialmente a da História da Arte). O estudioso, como ela diz, deve "interrogar as operações imaginantes na sua relação com o que constitui o sujeito falante e sociável” (p. 40). Da percepção desse papel crucial da imagem na própria constituição da sociedade, ela retira outra conclusão, de cunho político: "É porque a capacidade do sujeito de produzir imagens faz parte de uma economia constituinte do desejo que as instituiçôes que constituíram seu poder tomaram o cuidado tanto de interditar as imagens quando de controlar a produção de seus efeitos" (p. 41). O exemplo maior que ela dá, e não poderia ser diferente, lembrando suas pesquisas sobre os ícones bizantinos, é o cristianismo e suas restriçôes/ oposiçôes às imagens — cujo ápice não é nem mesmo o iconoclasmo bizantino, mas as pretensas imagens aqueiropoiéticas, não produzidas pela mão (e, portanto, não sendo frutos da operação imaginante e desejante) do homem.

Na sequência, temos três textos com uma abordagem mais estritamente filosófica, e que nos forçam a deslocar o olhar de historiador. Em "Imagem, mimesis \& méthexis", Jean-Luc Nancy discute, sobretudo, os dois conceitos do título: se mímesis nos é familiar (basta lembrar a extensa bibliografia sobre o tema, na qual se destaca o incontornável livro de Erich Auerbach ${ }^{5}$ ), méthexis (que poderíamos traduzir sucintamente por "participação") o é bem menos. Sua proposta é de que ambas devem ser consideradas de forma imbricada na imagem. Como exemplo, cita as máscaras funerárias romanas, que estão na origem do próprio termo "imago": desde o momento de sua modelagem, "a mímesis modula a méthexis pela qual os viventes partilham a morte do morto" (p. 59). A imagem é o efeito do desejo (do morto, nesse caso). Assim, após Mondzain, Nancy também retoma a noção de desejo, fundamental tanto na produção quanto na recepção da imagem, e que os historiadores em geral deixam de lado (como de resto tudo que se remete a ideias psicanalíticas). Decerto, não se trata de tarefa fácil, porém nem por isso deve ser eludida: não se está convidando a fazer uma análise psicanalítica de uma imagem (e o famoso e duvidoso exemplo de Freud com a pintura de Leonardo da Vinci mostra bem

\footnotetext{
${ }^{5}$ AUERBACH, Erich. Mimesis. A representação da realidade na literatura ocidental. São Paulo: Perspectiva, 2004.
} 
os perigos de tal empreendimento ${ }^{6}$ ), mas a considerá-la mais que representação e mais que objeto: deve-se analisar o poder que ela tem de mover o espectador (e não há que se esquecer que o historiador, diante da imagem, é sempre um espectador — ainda que não aquele para o qual ela foi inicialmente fabricada).

Partindo de uma obra da passagem do século XIII para o XIV, o Speculum divinorum et quorundam naturalium, de Henri Bate, que considera a imagem como um ente, Emanuele Coccia se propóe no quarto capítulo a analisar portanto a ontologia da imagem, ou o que chama de "ser do sensível" (p. 77). Seu grande exemplo são os espelhos - que produzem imagens que certamente não serão utilizadas como fontes diretas pelos historiadores, mas cujo funcionamento leva a refletir a respeito das capacidades e particularidades das imagens.

Dando continuidade à obra, no quinto capítulo seu organizador retoma o conceito de ídolo — não mais segundo a ótica cristã, mas na obra de Heidegger. A plasticidade do conceito, que pode soar simplesmente anacrônica a um historiador, faz lembrar que as palavras assumem diferentes sentidos ao longo do tempo e que é enriquecedor conhecê-los e a suas transformaçóes.

No capítulo que tem a perspectiva mais marcadamente histórica do livro, Hans Belting analisa funções e representações da janela, apontando as diferenças entre a cultura ocidental e a oriental. Uma das principais

\footnotetext{
${ }^{6}$ FREUD, Sigmund. Leonardo da Vinci e uma lembrança de sua infância: o Moisés de Michelângelo. Rio de Janeiro: Imago, 1997.
}

contribuições é apontar como a metáfora albertiana, comum na definição da noção de perspectiva, não vale para o Oriente, em que a janela não se abre para o mundo, mas filtra a luz e a ornamentaliza, geometrizando-a. Como ele lembra, e é sempre importante reforçar, não se deve considerar a cultura ocidental como universal, e as demais como casos particulares. $\mathrm{O}$ corpus iconográfico apresentado por Belting é muito bem escolhido, constituindo-se como um discurso próprio, complementar ao textual.

No sétimo capítulo, Horst Bredenkamp estuda exemplos de imagens que poderíamos chamar, à primeira vista, de ilustraçóes: trata-se de imagens acompanhando textos de ciências naturais, em diferentes momentos históricos. Mas mais do que simplesmente "ilustrar", tais imagens (sobretudo desenhos, nos casos por ele analisados) são exemplos claros de como se pensa por imagens, ou, dito de outra forma, como o desenho pode ser o "medium do pensamento" (p. 150). Ele destaca tais desenhos do campo do trabalho artístico, considerando-os como o "primeiro vestígio do corpo sobre o papel, o pensamento em sua mais elevada imediaticidade possível" (p. 161). Nesse sentido, tais imagens não poderiam ser melhores fontes para os historiadores (sobretudo os da história da ciência).

No capítulo seguinte, W. J. T. Mitchell retorna a esse tema, a relaçáo entre pensamento e imagem, mas não para explorar a função mediadora das imagens, e sim seu papel de sujeito. Ou, mais precisamente, como ele coloca no título, saber "o que as imagens realmente querem" (p. 165). Nes- 
se texto (originalmente publicado na revista October de 1996, no qual ele retoma a famosa interrogação de seu livro Picture Theory, de 1994, reforçada pelo advérbio "realmente"), sua primeira tarefa é buscar justificar a validade da pergunta, já que em princípio ela pode causar estranheza. No entanto, em nosso entender, ele não ataca de fato o problema, apoiando-se mais na iconografia (como demonstram os exemplos que fornece, como o do famoso cartaz de propaganda para alistamento do exército americano, com a imagem de Tio Sam, p. 175). Na conclusão de seu texto, Mitchell torna-se, literalmente, porta-voz das imagens (como deixa perceber quando diz: "Mas isso é tudo o que queremos? Ou, mais especificamente, é isso tudo o que as imagens querem?", p. 186). E aqui residem novos problemas, porque dentre esses supostos "desejos" das imagens, além de alguns de caráter genérico (como elas não quererem simplesmente ser transformadas em linguagem), estão outros passíveis de discussão, como seu convite à volta a "uma hermenêutica que retorne ao gesto inicial da iconologia do historiador da arte Erwin Panofsky” (p. 187), ou sua defesa de que as imagens não querem ser interpretadas. A última frase do capítulo chega mesmo a um impasse tautológico: "O que as imagens querem, em última instância, é simplesmente serem perguntadas sobre o que querem, tendo em conta que a resposta pode muito bem ser 'nada'" (p. 187). Como fazer tais perguntas?

Outras críticas podem ser levantadas, de forma mais elaborada, como o faz Jacques Rancière no capítulo que se segue. Nele, o filósofo francês não se limita a discutir esse texto, e dialoga com o conjunto da obra de Mitchell - que, é importante lembrar, é um dos principais nomes da chamada iconic turn, a virada icônica, ou pictorial turn, como ele se refere com mais frequência, ambas batizadas a partir da linguistic turn. É justamente daí que parte Rancière: em primeiro lugar, ele se interroga sobre que virada linguística seria essa. Seria a lacaniana, da materialidade do significante, ou a derridiana, em que há a primazia da fala em detrimento do traço gráfico? E, portanto, a virada pictórica seria a oposição a uma dessas situaçóes — ou a ambas? Como ele aponta, é certo que houve uma mudança nos últimos anos, tanto no que concerne a situaçôes práticas (como a ofensiva iconoclasta dos talibãs ao destruírem os Budas de Bamiyan, por exemplo, o que pressupóe uma requalificação de obras consideradas patrimônio da humanidade a imagens da divindade) quanto a posturas teóricas (como a do próprio Mitchell, que demonstrou em vários momentos de sua obra os modos de funcionamento das imagens, com suas condensações e deslocamentos, fazendo "ver uma coisa em uma outra ou por uma outra”, p. 193). Mas como Rancière aponta, Mitchell vai mais além, e sua virada pictórica seria o "retorno do recalcado": para responder à crítica a uma suposta inconsistência da imagem, ele insiste na vitalidade desta. Como ele diz, para o americano "as imagens não são reflexos, sombras ou artifícios, são seres viventes, quer dizer, organismos dotados de desejos" (p. 194). Mas quem deseja são os fazedores de imagens e seus consumidores, 
que (se) projetam nelas: "se amamos vê-las, é pela capacidade que temos de lhes emprestar ou de lhes subtrair ao mesmo tempo vida e vontade” (p. 200), escreve Rancière. E este propõe, em lugar de ver as imagens como viventes, dar-lhes a consistência de "quase-corpos", pois “o que constitui a imagem é a operação que transforma uma corporeidade em outra” (p. 200). Como exemplo, ele cita as "imagens reais" de Alfredo Jaar representando o genocídio em Ruanda: elas mostram palavras inscritas sobre caixóes negros nos quais estão fechadas fotografias dos corpos ausentes _ “ "quer dizer que ele lhes dá um outro corpo, um corpo e uma história singular em lugar de um corpo anônimo da vítima de um massacre de massa” (p. 200).

Depois desses dois textos, que constituem o ponto mais instigante do livro, a última parte é dedicada a um texto isolado de Georges Didi-Huberman, autor que foi descoberto há poucos anos em nosso país e se tornou a grande referência nos estudos sobre as imagens (ou de uma história das imagens, termo por ele mais utilizado que o visual studies de Mitchell). Ele parte de duas questôes aparentemente das mais simples: a primeira, que ele qualifica de inocente, ainda que útil, é a de saber de que uma imagem é uma imagem. Muita tinta já foi gasta para respondê-la, e não é ela que atrai sua atenção, e sim uma segunda, que chama de tola e maldosa (mas só aparentemente), “a quem" (no sentido do "de quem", da pertença que a expressão francesa à qui significa) é uma imagem ('Diz-se: 'tirar uma foto'. Mas o que se tira, a quem se tira exatamente? $\mathrm{E}$ não é preciso devolvê-la a quem de direito?", p. 205). Ou seja, não se trata de discutir o conteúdo da imagem, seu referente etc., como uma resposta — ela sim verdadeiramente tola - poderia dar. Seu objeto de reflexão é a obra de Harun Farocki, cineasta/documentarista/artista de origem alemã morto em 2014. Como um verdadeiro arqueólogo e montador de imagens, Farocki obtinha, remontava e expunha imagens mostrando o funcionamento de nossas sociedades (desde uma sessão de pose para a revista Playboy até técnicas militares) que deveriam permanecer escondidas do público em geral. Jogando com as palavras voir (ver) e recevoir (receber - para o qual podemos oferecer outra tradução que a do livro: em recevoir há não só voir, mas revoir, rever, e ce, esse: receber e rever isso/esse), Didi-Huberman discute como Farocki conseguiu nos restituir imagens do mundo ("imagens operadoras", um termo muito mais apropriado que viventes, no que ele tem de fazer pensar no modo de funcionamento das imagens), mais do que simplesmente se apropriar delas. São imagens que constituem um bem comum e que ele retorna à comunidade, em um gesto que mostra o alcance político, militante que podem ter as imagens.

Na sequência, após os créditos das imagens, são apresentadas notas biográficas dos autores e dos tradutores. A preocupação em fornecer indicações bibliográficas em português das principais obras dos autores enriquece a edição, embora algumas estejam faltando, como Ensaios de ego-história, de Pierre Nora, pelas Ediçóes 70, ou Sobre o olhar, de John Berger, pela Gustavo Gili.

Mas há outras ressalvas que podem ser 
feitas em relação à edição, como nas notas de tradução, que nos parecem por vezes trazer informaçôes desnecessárias, pois implicam um leitor demasiado desconhecedor de alguns termos técnicos, mas não de todos - $\mathrm{e}$ a seleção dos termos que ganharão nota explicativa não é clara. Também é questionável o critério de traduçáo dos nomes de autores antigos ou medievais, sobretudo quando, além disso, a opçáo por determinada tradução não se mantém, como é o caso de Tertuliano, ora grafado em português, ora em francês. E, por fim, uma crítica que se pode fazer ao organizador do volume é a ausência da referência (e mesmo da própria indicação) da procedência dos textos que não foram originalmente apresentados no Seminário.
À guisa de conclusão, voltemo-nos a um detalhe, que diz respeito ainda mais diretamente aos leitores historiadores da obra resenhada. É significativo que no primeiro capítulo, de Boehm, quando ele lista as disciplinas que constroem conhecimentos sobre as imagens, não liste a História. Estão lá História da Arte, Arqueologia, Paleontologia, Antropologia, Teologia, Psicanálise, Literatura e História das Ciências. A História estaria implícita nas duas Histórias citadas? Esquecimento por parte do autor? Seja como for, ato falho, má vontade, ou mesmo esquecimento, isso demonstra que os historiadores ainda não estão entre os maiores frequentadores das imagens. Façamos votos de que isso mude. 